Organisation de Coopération et de Développement Economiques

Organisation for Economic Co-operation and Development

05-Mar-2004

ENVIRONMENT DIRECTORATE

English - Or. English

JOINT MEETING OF THE CHEMICALS COMMITTEE AND

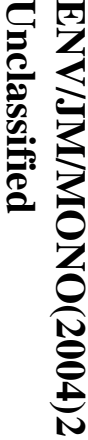

THE WORKING PARTY ON CHEMICALS, PESTICIDES AND BIOTECHNOLOGY

GUIDANCE DOCUMENT FOR THE CONDUCT OF SKIN ABSORPTION STUDIES

OECD SERIES ON TESTING AND ASSESSMENT

Number 28

JT00159305

Document complet disponible sur OLIS dans son format d'origine

Complete document available on OLIS in its original format 

OECD Environmental Health and Safety Publications

Series on Testing and Assessment

No. 28

\section{GUIDANCE DOCUMENT FOR THE CONDUCT OF SKIN ABSORPTION STUDIES}

Environment Directorate

ORGANISATION FOR ECONOMIC CO-OPERATION AND DEVELOPMENT

Paris

March 2004 


\section{Also published in the Series on Testing and Assessment:}

No. 1, Guidance Document for the Development of OECD Guidelines for Testing of Chemicals (1993; reformatted 1995)

No. 2, Detailed Review Paper on Biodegradability Testing (1995)

No. 3, Guidance Document for Aquatic Effects Assessment (1995)

No. 4, Report of the OECD Workshop on Environmental Hazard/Risk Assessment (1995)

No. 5, Report of the SETAC/OECD Workshop on Avian Toxicity Testing (1996)

No. 6, Report of the Final Ring-test of the Daphnia magna Reproduction Test (1997)

No. 7, Guidance Document on Direct Phototransformation of Chemicals in Water (1997)

No. 8, Report of the OECD Workshop on Sharing Information about New Industrial Chemicals Assessment (1997)

No. 9, Guidance Document for the Conduct of Studies of Occupational Exposure to Pesticides during Agricultural Application (1997)

No.10, Report of the OECD Workshop on Statistical Analysis of Aquatic Toxicity Data (1998)

No. 11, Detailed Review Paper on Aquatic Testing Methods for Pesticides and industrial Chemicals (1998)

No. 12, Detailed Review Document on Classification Systems for Germ Cell Mutagenicity in OECD Member Countries (1998)

No. 13, Detailed Review Document on Classification Systems for Sensitising Substances in OECD Member Countries 1998)

No. 14, Detailed Review Document on Classification Systems for Eye Irritation/Corrosion in OECD Member Countries (1998)

No. 15, Detailed Review Document on Classification Systems for Reproductive Toxicity in OECD Member Countries (1998) 
No. 16, Detailed Review Document on Classification Systems for Skin Irritation/Corrosion in OECD Member Countries (1998)

No. 17, Environmental Exposure Assessment Strategies for Existing Industrial Chemicals in OECD Member Countries (1999)

No. 18, Report of the OECD Workshop on Improving the Use of Monitoring Data in the Exposure Assessment of Industrial Chemicals (2000)

No. 19, Draft Guidance Document on the Recognition, Assessment and Use of Clinical Signs as Humane Endpoints for Experimental Animals used in Safety Evaluation (1999)

No. 20, Revised Draft Guidance Document for Neurotoxicity Testing (in preparation)

No. 21, Detailed Review Paper: Appraisal of Test Methods for Sex Hormone Disrupting Chemicals (2000)

No. 22, Guidance Document for the Performance of Outdoor Monolith Lysimeter Studies (2000)

No. 23, Guidance Document on Aquatic Toxicity Testing of Difficult Substances and Mixtures (2000)

No. 24, Guidance Document on Acute Oral Toxicity Testing (2001)

No. 25, Detailed Review Document on Hazard Classification Systems for Specifics Target Organ Systemic Toxicity Repeated Exposure in OECD Member Countries (2001)

No. 26, Revised Analysis of Responses Received from Member Countries to the Questionnaire on Regulatory Acute Toxicity Data Needs (2001)

No 27, Guidance Document on the Use of the Harmonised System for the Classification of Chemicals Which are Hazardous for the Aquatic Environment (2001)

No 28, Guidance Document for the Conduct of Skin Absorption Studies (2004)

No 29, Draft Guidance Document on Transformation/Dissolution of Metals and Metal Compounds in Aqueous Media (2001) 
No 30, Detailed Review Document on Hazard Classification Systems for Mixtures (2001)

No 31, Detailed Review Paper on Non-Genotoxic Carcinogens Detection: The Performance of In-Vitro Cell Transformation Assays (draft)

No. 32, Guidance Notes for Analysis and Evaluation of Repeat-Dose Toxicity Studies (2000)

No. 33, Harmonised Integrated Classification System for Human Health and Environmental Hazards of Chemical Substances and Mixtures(2001)

No. 34, Guidance Document on the Development, Validation and Regulatory Acceptance of New and Updated Internationally Acceptable Test Methods in Hazard Assessment (in preparation)

No. 35, Guidance notes for analysis and evaluation of chronic toxicity and carcinogenicity studies (2002)

No. 36, Report of the OECD/UNEP Workshop on the use of Multimedia Models for estimating overall Environmental Presistence and long range Transport in the context of PBTS/POPS Assessment (2002)

No.37, Detailed Review Document on Classification Systems for Substances Which Pose an Aspiration Hazard (2002)

No. 38, Detailed Background Review of the Uterotrophic Assay Summary of the Available Literature in Support of the Project of the OECD Task Force on Endocrine Disrupters Testing and Assessment (EDTA) to Standardise and Validate the Uterotrophic Assay (2003)

No. 39, Guidance Document on Acute Inhalation Toxicity Testing (in preparation)

No. 40, Detailed Review Document on Classification in OECD Member Countries of Substances and Mixtures Which Cause Respiratory Tract Irritation and Corrosion (2003)

No.41, Detailed Review Document on Classification in OECD Member Countries of Substances and Mixtures which in Contact with Water Release Toxic Gases (2003)

No. 42, Draft Guidance Document on Reporting Summary Information on Environmental, Occupational and Consumer Exposure (in preparation) 
No. 43, Draft Guidance Document on Reproductive Toxicity Testing and Assessment (in preparation)

No. 44, Descriptions of Selected Key Generic Terms used in Chemical Hazard/Risk Assessment (2003)

No. 45, Draft Guidance Document on the Use of Multimedia Models for Estimating Overall Environmental Persistence and Long-range Transport (2004)

\section{(C) OECD 2003}

Applications for permission to reproduce or translate all or part of this material should be made to: Head of Publications Service, OECD, 2 rue André-Pascal, 75775 Paris Cedex 16, France 


\begin{abstract}
About the OECD
The Organisation for Economic Co-operation and Development (OECD) is an intergovernmental organisation in which representatives of 30 industrialised countries in North America, Europe and the Pacific, as well as the European Commission, meet to co-ordinate and harmonise policies, discuss issues of mutual concern, and work together to respond to international problems. Most of the OECD's work is carried out by more than 200 specialised Committees and subsidiary groups composed of Member country delegates. Observers from several countries with special status at the OECD, and from interested international organisations, attend many of the OECD's Workshops and other meetings. Committees and subsidiary groups are served by the OECD Secretariat, located in Paris, France, which is organised into Directorates and Divisions.

The work of the OECD related to chemical safety is carried out in the Environment, Health and Safety Programme. As part of its work on chemical testing, the OECD has issued several Council Decisions and Recommendations (the former legally binding on member countries), as well as numerous Guidance Documents and technical reports. The best known of these publications, the OECD Test Guidelines, is a collection of methods used to assess the hazards of chemicals and of chemical preparations. These methods cover tests for physical and chemical properties, effects on human health and wildlife, and accumulation and degradation in the environment. The OECD Test Guidelines are recognised world-wide as the standard reference tool for chemical testing.

More information about the Environment, Health and Safety Programme and its publications (including the Test Guidelines) is available on the OECD's World Wide Web site http://www.oecd.org/ehs/.

The Environment, Health and Safety Programme co-operates closely with other international organisations. This document was produced within the framework of the Inter-Organisation Programme for the Sound Management of Chemicals (IOMC).

The Inter-Organization Programme for the Sound Management of Chemicals (IOMC) was established in 1995 by UNEP, ILO, FAO, WHO, UNIDO and the OECD (the Participating Organisations), following recommendations made by the 1992 UN Conference on Environment and Development to strengthen co-operation and increase international coordination in the field of chemical safety. UNITAR joined the IOMC in 1997 to become the seventh Participating Organisation. The purpose of the IOMC is to promote co-ordination of the policies and activities pursued by the Participating Organisations, jointly or separately, to achieve the sound management of chemicals in relation to human health and the environment.
\end{abstract}


This publication is available electronically, at no charge.

For the complete text of this and many other Environment, Health and Safety publications, consult the OECD's World Wide Web site

(http://www.oecd.org/document/21/0,2340,en_2649_34365_1862357_1_1_1_1,00.html)

or contact:

OECD Environment Directorate,

Environment, Health and Safety Division

2 rue André-Pascal

75775 Paris Cedex 16

France

Fax: (33-1) 45241675

E-mail: ehscont@oecd.org 


\section{TABLE OF CONTENTS}






\section{HISTORY OF THE DOCUMENT}

1. The development of the OECD Guidance Document for the conduct of skin absorption studies was agreed at a meeting of the OECD Extended Steering Group on the Development of in vitro and in vivo Percutaneous Absorption Methods as Test Guidelines in Research Triangle Park, NC, USA in October 1997. The need for the Guidance Document became apparent when national experts from a number of Member countries could not agree on the possibilities and limitations of the in vitro test. A Guidance Document was considered the most suitable option to explain Member country's concerns and options for use of the in vitro method.

2. The Toxicology Expert Group of the European Crop Protection Association (ECPA) volunteered to assist in the preparation of a first draft of the Guidance Document, in addition to the revision of the draft Test Guidelines. A sub-group of technical experts from ECPA was formed to undertake this task.

3. Several meetings of the ECPA Dermal Absorption Group took place during 1998 and 1999. In preparing the first draft suggestions made at the Meeting of the OECD National Co-ordinators of the Test Guidelines Programme in August 1998 (WNT 10) and at an OECD Steering Group Meeting in Lodz, Poland in June 1999 were taken into account.

4. In November 1999, an OECD Expert Group was established to reconsider the first draft and to gain consensus on specific aspects of the Guidance Document. This Expert Group comprised Angela Auletta (US EPA); Bob Bronaugh (US FDA); Jon Heylings (Syngenta, UK); John Worgan (Health Canada)and Errol Zeiger. The OECD Secretariat provided practical assistance and technical guidance.

5. Following further discussion between the WNT and the technical expert groups, the revised Guidance Document was presented to the National Co-ordinators meeting in May 2000 (WNT 12). The Guidance Document was endorsed and declassified by the Joint Meeting of the Chemicals Committee and Working Group on Chemicals, Pesticides and Biotechnology in May 2001.

6. The Guidance Document provides additional technical background to both the in vivo and in vitro methods for skin absorption as described in Test Guidelines 427 and 428 respectively. It further highlights explains the use of the outcome of these tests for hazard and risk assessment purposes. 


\section{INTRODUCTION}

7. Some of the procedures required by the OECD guidelines for the conduct of skin absorption studies (OECD 427 and 428) need further detail before scientists unfamiliar with such procedures can undertake these types of studies correctly. Furthermore, some users of the guidelines from specific industries (e.g. cosmetic, detergent and agrochemical) may have requirements, which are difficult to embody within guidelines of broad applicability. For these reasons, this guidance document has been prepared to support technical aspects of the OECD skin absorption test guidelines (1) (2).

\section{INITIAL CONSIDERATIONS}

8. The methods for measuring skin absorption and dermal delivery can be divided into two categories: in vivo and in vitro. In vivo methods in experimental animals have traditionally been used to assess skin absorption for regulatory purposes and national guidelines are available (3)(4)(5). They have some advantages over in vitro methods, which include generation of systemic kinetic and metabolic information. The disadvantages are the use of live animals, the need for radio-labelled material to facilitate reliable results, difficulties in determining the early absorption phase and the differences in permeability of the preferred species (rat) and human skin. Animal skin is generally more permeable and therefore may overestimate human percutaneous absorption (6)(7)(8).

9. The in vitro method has been described in detail in a number of monographs published over a 10-year period $(9)(10)(11)(12)(13)(14)(15)(16)(17)$. The advantages of the in vitro method over the in vivo method are that it can be used equally well with skin from humans and other species; several replicate measurements can be made from the same or a number of different subjects; live animals are not used; intended use exposure conditions can be studied; a wider range of physical forms can be investigated (i.e. including solids and granules); the impact of skin damage on absorption can be assessed avoiding ethical issues. In addition, the in vitro method can be used for non-radio-labelled test substances, which are extensively metabolised. A limitation associated with an in vitro approach is that sink conditions of the peripheral blood flow may not be fully reproduced. However, skin absorption is primarily a passive process and studies undertaken using appropriate in vitro experimental conditions have produced data for a wide range of chemicals that demonstrate the usefulness of this method $(18)(19)(20)(21)(22)(23)(24)(25)(26)(27)(28)(29)(30)(31)(32)(33)(34)(35)$ (36)(37)(38)(39)(40)(41). Such methods have found use in, for example, comparing delivery of chemicals into and through skin from different formulations and can also provide useful models for the assessment of risk due to percutaneous absorption in humans.

10. National regulatory authorities may have different preferences for in vivo and/or in vitro skin absorption studies, so the choice of which method(s) to use should be in line with the requirements of the specific regulatory bodies/authorities. The use of in vivo and/or in vitro methods will depend on the situation being evaluated. In vivo data may be used alone. However, it may be possible, depending on the intended use of the test substance, to undertake only an in vitro study for a first evaluation of skin penetration. Where a more refined evaluation of dermal absorption is required, in vitro and in vivo data are considered together. It is advisable to contact the appropriate regulatory authority to confirm the most relevant and adequate test protocol(s) before conducting skin absorption studies.

11. The principle factors relating to the experimental conditions for in vitro skin absorption studies are discussed in detail in this guidance document.

12. To demonstrate the performance and reliability of the test system in the performing laboratory, the results for relevant reference chemicals should be available and in agreement with 
published literature, e.g. (12) for the method used. This alternative could be met by testing an appropriate reference substance (preferably of a lipophilicity close to the test substance) concurrently with the test substance or by providing adequate historical data for a number of reference substances of different lipophilicity (Typical examples of reference chemicals that have been extensively studied in vivo and in vitro, include caffeine (log $\left.\mathrm{P}_{\mathrm{ow}} 0.01\right)$, benzoic acid $\left(\log \mathrm{P}_{\mathrm{ow}} 1.83\right)$ and testosterone $(\log$ $\mathrm{P}_{\text {ow }} 3.32$ ).

\section{PRINCIPLE OF THE TESTS}

13. The methods for measuring dermal absorption and dermal delivery can be divided into two categories: in vivo and in vitro. The methods study the diffusion of a test substance from a test preparation through the skin barrier and into the skin.

\section{In Vivo}

14. The rat is the most commonly used species for the in vivo test. In rats, the application site should be about $10 \mathrm{~cm} 2$ and should be defined by a device, which is secured on the skin surface. The test preparation is applied to the surface of skin. The test preparation remains on the skin for a specified period of time, relating to potential human exposure, then the test preparation is removed by an appropriate cleansing procedure. During exposure, animals are housed individually in metabolism cages from which excreta are collected. When appropriate, exhaled volatile metabolites may also be collected. At the end of the study, the animals may be anaesthetised and the dislodgeable dose is washed from the skin surface. The animals are then terminated and the amount of dose associated with the skin, the carcass and in excreta, is determined. These data allow for an estimate of the total recovery of the test substance. The skin absorption of the test substance can be expressed as the percentage of dose absorbed per unit time or in terms of an average absorption rate per unit area of skin (e.g., $\mu \mathrm{g} / \mathrm{cm} 2 / \mathrm{hr}$ ).

15. Test substance remaining in the skin after wash-off will normally move over time by one of three processes, it may be sloughed off by desquamation, it may be ingested when the animal grooms itself, or it may diffuse into the animal to become systemically available. Suitable technical procedures will be required to prevent grooming of the treated site, and to prevent desquamed skin from falling into the urine/faeces collection system. This is crucial to avoid overestimation of the systemically absorbed dose.

\section{In Vitro}

16. Skin from many mammalian species, including humans, can be used. Several references discuss interspecies comparison of dermal absorption and absorption through different skin regions $(11)(12)(16)(25)$. The test preparation is applied to the surface of excised skin, which is mounted in a diffusion cell. The receptor fluid, which must have an adequate capacity to solubilise the test substance, is maintained in contact with the underside of the skin from the time of application until the end of the collection of the receptor fluid. The test preparation remains on the skin for a specified period of time, relating to potential human exposure, and then the test preparation is removed by an appropriate cleansing procedure. The receptor fluid is sampled at time points throughout the experiment to ascertain the mass (and possibly rate) of the test substance (including any significant metabolite) passing through the skin. At the end of the study, the dislodgeable dose, the amount associated with the skin and the amount in the receptor fluid is determined. These data are necessary to calculate the total skin absorption, and allow for an estimate of the total recovery of the test substance. 
The skin absorption of the test substance is expressed as the percentage, amount or rate of absorption per unit time, or in the case of infinite dose applications, as a permeability constant.

\section{DESCRIPTION OF THE METHODS}

\section{Selection of Animal Species}

\section{In Vivo}

17. No further guidance considered necessary

\section{In Vitro}

18. Skin preparations from human or animal sources including hairless animals can be used (9)(10)(11)(12)(13)(14)(15)(33)(35)(36)(37). Reconstituted human skin models can be used if data from reference chemicals are consistent with those in the published literature. In most cases, these studies are intended to predict skin absorption in humans. Therefore, use of human skin is most relevant. However, for regulatory or practical reasons, other animal species may have to be used, usually rats or pigs. Rat skin is often used because the majority of regulatory toxicity studies are in this species. Furthermore, existing legislation for assessment of in vivo dermal absorption also stipulate the use of this species (3)(4)(5). Pig skin is used because of its similarity to human skin in terms of its morphology and permeability characteristics, making it a practical alternative (13). Viable skin is preferred but it is recognised that viable skin is not always easily available. Furthermore, for reasons of comparability, standardised non-viable skin may have advantages. Therefore, non-viable skin can also be used provided that the integrity of the skin can be demonstrated.

\section{Number and Sex of Animals}

\section{In Vivo}

19. No further guidance considered necessary

\section{Housing and Feeding Conditions}

\section{In Vivo}

20. No further guidance considered necessary.

\section{Preparation of Animals}

\section{In Vivo}

21. Animals should be housed and fed according to conventional procedures. An acclimatisation period of at least 5 days prior to the application of the test preparation is required. Feed and water should be freely available (15). At least 16 hours before treatment, the application site should be prepared. For example, in the rat, hair on the shoulders and back is removed with animal hair clippers (1)(15). Care is taken to ensure that the skin surface is free of abrasions, which will inevitably increase 
percutaneous absorption (15). Consequently shaving of the application site should be avoided. The area must be large enough to allow reliable calculation of the absorbed amount of test substance per $\mathrm{cm} 2$ skin, preferably at least $10 \mathrm{~cm} 2(15)$. The skin may be washed prior to dosing with a suitable medium, such as water or a mild detergent (15). However, careful consideration must be given to the possibility of modifying the skin or its barrier properties. The reasons for washing and the choice of the cleansing agent should be justified in the report. After preparation, the animals are placed in their individual metabolism cages. Before application animals are marked to permit individual identification.

\section{Diffusion Cell}

\section{In Vitro}

22. There are several types of diffusion cells, which all consist of a donor chamber and a receptor chamber between which the skin is positioned (9)(11)(16)(45)(46). In a set of diffusion cells, each cell has the same surface area, typically in the range 0.3 to $5 \mathrm{~cm}^{2}$. The skin preparation is positioned in the cell with the stratum corneum uppermost. The cell should provide a good seal around the skin, and enable good mixing and easy sampling of the receptor fluid. It must be made from an inert material, such as glass or PTFE, to minimise interaction with the test substance. The design of the cells should allow accurate temperature control of the skin and receptor fluid. Either static or flowthrough cells are acceptable (43)(45)(46)(47). Donor chamber design should allow for occlusion and easy removal of the test preparation, if required.

\section{Receptor Fluid}

\section{In Vitro}

\section{Acceptable Receptor Fluids}

23. The selection of the receptor fluid must be compatible with the skin preparation and meet the key parameter of solubility of the test substance (not the test preparation) in the receptor fluid.

24. For non-viable skin preparations, the receptor fluids for evaluating water soluble compounds are usually saline solutions, $\mathrm{pH}$ 7.4. For lipophilic test substances the receptor fluid can contain organic solvents such as 1:1 ethanol:water or 6\% polyethylene glycol 20 oleyl ether in water (12)(13). Barrier integrity of skin must not be damaged. Thin preparations of sections of skin $(200 \mu \mathrm{m})$ have been shown to have increased susceptibility to barrier damage.

25. For metabolically active skin preparations, a physiological based receptor fluid, e.g. tissue culture medium should be used (10)(11)(12)(13)(14)(15). The limitation of using such a receptor fluid for non-polar test substances is the potential inadequate solubility of the test substance in the receptor fluid. This should be addressed by the addition of a modifier to the physiological fluid, typically $6 \%$ polyethylene glycol 20 oleyl ether (47) or 5\% bovine serum albumin (15).

26. For non-radio-labelled test substances the chosen receptor fluid should not interfere with the analytical methods employed.

\section{Solubility of Test Substance in Receptor Fluid}

27. It is imperative that solubility in the receptor fluid is not a rate-determining step in skin absorption $(12)(13)(15)(16)$. 
28. Normally in flow-through systems an adequate flow rate of receptor fluid will prevent back diffusion. In static systems it is particularly important to ensure satisfactory solubility. Ideally, an estimate of the likely maximum achieved concentration of test substance in receptor fluid should be made, based on previous in vivo or in vitro study data. Physicochemical data or experimental results should be used to show that about 10 times this concentration is achievable under the experimental conditions (15)(16). This will ensure that back diffusion is not significant. The absorption rate profile over the study duration can be used retrospectively to confirm that solubility was not rate limiting.

\section{Receptor Fluid Exchange /Flow Rate}

29. In static cells, the volume of the specific receptor fluid (typically $2-20 \mathrm{ml}$ ) has to be sufficient not to limit the dermal absorption of the test substance (44).

30. In flow-through cells the volume of the receptor fluid in the receptor chamber beneath the skin is typically $0.1-5 \mathrm{ml}$. This volume must be replenished continuously such that the rate of diffusion into the receptor fluid does not become a rate-limiting step (44).

31. Typical flow rates may be $9 \mathrm{ml} / \mathrm{hr}$ for a receptor chamber of $3 \mathrm{ml}$ ( 3 changes $/ \mathrm{hr}$ ), or $1.5 \mathrm{~mL}$ $/ \mathrm{hr}$ for a receptor chamber of 150-300 $\mu \mathrm{L}$ (5-10 changes/hr). A slower flow rate (i.e., representing $\sim 1$ change/hr) may sometimes be appropriate, particularly in the case of unlabeled test compound where analytical difficulties may result if the concentration of test material in receptor fluid is too low.

\section{Maintenance of Metabolic Activity}

32. Metabolic activity is not required to study dermal absorption of radio-labelled material, as this is a passive diffusion process. However, the biotransformation of the compound in skin prior to systemic absorption may be significant for some compounds. Where maintenance of metabolic activity is required (i.e., there is a requirement for the identification of metabolites) it is necessary to demonstrate that the relevant metabolic activity is maintained for the duration of the study $(11)(15)$.

33. It is known that changes occur in the metabolic capacity of skin once excised from the donor (11)(15). There is usually a rapid reduction in glutathione and phase I enzymes, and a slower reduction in energy metabolism. Some enzyme systems such as esterases remain active even after freezing. The use of cell culture media or other physiologically compatible receptor fluids will increase the duration of metabolic activity. The most widely used indicator of skin viability has been glucose utilization (48) since energy metabolism is critical to metabolic integrity.

34. The degree of metabolism in vitro will depend on the residence time of the test substance in the metabolically active tissue layer (normally the epidermis). A longer residence time provides greater opportunity for metabolism; residence time is often shorter in vivo than in vitro (16).

\section{Skin Preparations}

\section{In Vitro}

35. Dermal absorption through human skin is normally assessed using abdominal or breast skin $(12)(14)(15)(49)(50)(51)$. When pig skin is used, the most commonly used sites are the flank and the ear; skin from the back or limb is also typically used (13).

36. In the case of the rat, dorsal or ventral skin may be used but dorsal skin should be used if the study is designed to correspond with the in vivo application site (12). 
37. The method of preparation of epidermal membranes varies across species due to the inherent differences in skin morphology and follicle depth (12)(13)(15). Commonly, heat separation is used for human and pig skin $\left(60^{\circ} \mathrm{C}\right.$ for one to two minutes; the epidermal membrane is peeled from the dermis using forceps). Chemical separation is used to prepare rat epidermal membranes (2M sodium bromide). Enzymatic separation using protease or bacterial collagenase is also effective.

38. Split-thickness skin (typically $200-400 \mu \mathrm{m}$ thick) is prepared using a dermatome.

39. Full thickness skin may be used but excessive thickness ( $c a .>1 \mathrm{~mm}$ ) should be avoided unless specifically required for determination of the test substance and/or metabolites distribution in layers of the skin.

\section{Storage of Skin Preparations}

40. For the assessment of the percutaneous absorption of a test substance, excised skin can be used immediately or stored frozen prior to use (52)(53)(54). There is evidence available that appropriate storage has no relevant effect on the in vitro permeability of both human and animal skin (52). The ability to use stored skin from human donors post mortem rather than being limited by the supply from plastic surgery is particularly important in the practical use of the in vitro technique.

41. Animal and human skin can be stored for several months at $-20^{\circ} \mathrm{C}$. No changes in human skin permeability to tritiated water have been reported in fresh skin stored for up to 3 days at $10^{\circ} \mathrm{C}$ or in frozen skin stored for up to 466 days (52). It is preferable to remove subcutaneous tissue before storage as this facilitates handling at later times. Epidermal membranes can be stored at $-20^{\circ} \mathrm{C}$ with no changes reported in their permeability compared with fresh skin (53). It is inadvisable to refreeze and thaw skin specimens as this can increase the permeability (53). It has been shown that skin stored at $-20^{\circ} \mathrm{C}$ exhibited no change in permeability compared with fresh skin. Skin should not be stored at very low temperatures since it has been shown that the storage of skin at $-80^{\circ} \mathrm{C}$ can enhance permeability (54). However, another study has reported that the barrier integrity of dermatomed human skin (200 $\mu \mathrm{m})$ can deteriorate during frozen storage at $-20^{\circ} \mathrm{C}$ during storage intervals ranging from 2 to 12 months (55). This effect does not seem to depend on the length of storage and so cannot be predicted. It is necessary that the barrier integrity of skin be verified after frozen storage using methods described in the Skin Preparation Integrity section of this guidance document.

\section{Skin Preparation Integrity}

\section{In Vitro}

42. It is critical that the integrity of the stratum corneum is retained during skin/membrane storage and preparation, and that the selected preparation method can be shown not to cause physical damage.

43. There are various methods that can be used to evaluate skin preparation integrity $(12)(13)(15)(56)(57)$. However, care should be taken that the integrity check is relevant to penetration by the test substance. If integrity is diminished, then an over estimate of permeability will be made.

44. The first step in evaluating a skin preparation is to make a visual examination for physical damage, excluding unsuitable samples. Secondly, the skin sample must be mounted and allowed to equilibrate in the cell and allowed to hydrate, this will often close small holes such as open hair channels. It is recommended that any pre-study integrity evaluation procedure does not take longer than a few hours, and is performed just before application of the test preparation. 
45. Acceptable methods of integrity evaluation are listed below. One of the methods ( $\mathrm{a}, \mathrm{b}$ or $\mathrm{c})$ should be performed for each cell.

a) Pre-study integrity evaluation methods

- checking that electrical resistance to an alternating current, at up to 2 volts, is in the normal range for the skin type, or;

- checking that trans-epidermal water loss (TEWL) from the stratum corneum is in the normal range for the skin type, or;

- measuring the penetration characteristics of a reference material (e.g., tritiated water) may be suitable. However, any physical deterioration in the skin preparations (due to time at ambient temperature or hydration) may result in an overestimate of permeability.

46. Pre-study evaluation has the advantage that damaged skin can be eliminated before performing the test. It is essential to remove any liquid used and to allow the skin surface to dry before application of test preparation. The skin should be allowed to equilibrate with the receptor fluid for typically 10 to 30 minutes before dose application.

b) Concurrent integrity evaluation

47. Addition of a reference material to the test preparation (e.g., high specific activity ${ }^{3} \mathrm{H}$ Sucrose in a ${ }^{14} \mathrm{C}$-test substance formulation) can be a valuable method provided that the concentration of the reference material is low enough to avoid a contribution to the thermodynamics of the formulation, and that the difference between the $\log \mathrm{P}$ of the reference and test substance is not significant. For practical reasons this cannot be used for every test preparation.

c) Post-study integrity evaluation

48. Use of any of the methods given in a) above may be performed after the exposure to the test preparation. However, stratum corneum integrity may have been reduced during/after the study because of physical wash-off procedures or hydration/ degeneration or effects of the test formulation. Hence, post-study physical evaluation is usually only appropriate following certain short exposure studies (e.g., hair care products). Post-study data analysis can be used to identify damaged skin preparations by comparison to the mean absorption data for the other cells; the test substance penetrating damaged skin at a higher rate and earlier time than for intact membranes.

\section{Test Substance}

\section{In Vivo and In Vitro}

49. For practical reasons, the test substance ideally should be radio-labelled, in a metabolically stable position preferably with ${ }^{14} \mathrm{C}$, and of suitable radiochemical purity (ideally $>98 \%$ ). This allows for the evaluation of distribution and recovery of the test substance. In addition, it facilitates rapid, accurate, sensitive analysis of all components of the test system. The radio-labelled chemical may be diluted, when appropriate, with non-radio-labelled chemical. The specific activity and radiochemical purity of the test substance must be known (9)(12)(15)(16). 
50. Despite the advantages of using radio-labelled test substance, it is not always possible or practical to make a representative test preparation (e.g., for complex formulations such as microencapsulated or granular products). Furthermore, in many cases, for example industrial chemicals and their intermediates, surfactants and inorganic substances, radio-labelled test substance cannot be synthesised. In this situation, a non-radio-labelled chemical may be utilised if suitable validated assay procedures exist for the chemical in the relevant samples.

\section{Test Preparation}

\section{In Vivo and In Vitro}

51. The test preparation (e.g., the actual formulated material containing the test substance that is applied to the skin) should be the same (or a realistic surrogate) as that to which humans or other potential target species may be exposed. The test preparation is usually made by mixing the radiolabelled test substance with the blank preparation (commercial preparation excluding the test substance). It is critical that the labelled test substance is formulated to be representative of the nonlabelled test substance in the 'in-use' preparation. Wherever appropriate, dilutions are made according to the procedures recommended for normal use, which is often a dilution with water, in order to produce a solution or suspension $(9)(11)(16)(46)$.

52. Solids, such as powders, should be moistened with water to assist skin contact and quantitative and homogeneous application of the dose. Moistening will to some degree mimic the environmental humidity and the presence of perspiration as for normal 'in-use' conditions.

53. The stability and homogeneity of the test substance in the test preparation should be determined. For solid and semi-solid test formulations and for suspensions, the test substance uniformity within the formulation should be verified.

\section{Application to the Skin}

\section{In Vivo}

54. Immediately prior to dosing, the animal is removed from the metabolism cage. Usually, good animal handling restraint alone is adequate for test substance application, but animals may be sedated or lightly anaesthetised where necessary while manipulations are performed to prevent movement (1). The area of application should be clearly defined on the animal. The application area should normally be approximately $5-10 \%$ of the animal surface area, i.e. $10 \mathrm{~cm}^{2}$ for the rat $(200-250 \mathrm{~g} \mathrm{b.w.)}$. An application system should be used which consists of a raised support within which the test formulation is applied, it must be designed such that it does not to cause damage to the skin. The system must prevent the animal from interfering with the application site, while preventing any spreading of the chemical outside the defined area. A common procedure is for a ring (e.g. rubber O-ring, PTFE rings, disposable beakers, etc.) of an inert material to be securely glued to the skin over the clipped area before applying the test formulation using cyanoacrylate adhesive to confine the treated skin area (9)(11)(12)(15)(16). The applied dose should mimic the 'in-use' conditions. It should be given as an appropriate quantity of test preparation (usually as a volume) spread on the skin surface. $1-5 \mathrm{mg} / \mathrm{cm}^{2}$ or up to $10 \mu \mathrm{L} / \mathrm{cm}^{2}$ may be used. Larger amounts tend to run-off in actual exposure conditions (9)(12)(15)(16). Smaller volumes may be appropriate, based on the physicochemical properties of the test preparation, for example low viscosity liquids. If a spreader is used to evenly distribute the test preparation, it should be checked for retention of material and the applied dose should be corrected for these losses. The application system must be covered, e.g. a nylon gauze may be glued over the ring to protect the test preparation against unintentional removal or spreading. Dislocation of the ring by the 
animal can be prevented by placement of a collar or, in the rat, rubber tubing behind the forelegs or the neck (1)(18). Furthermore, the ring should be deep enough to account for non-occlusive conditions and to prevent the cover rubbing on the treated skin (11). Full occlusion over hydrates the stratum corneum and produces an artificial overestimate of penetration (10). The animals are finally returned to their individual metabolism cages.

55. In a typical study with radio-labelled test substance in the rat, an application of $300 \mathrm{kBq}-$ $500 \mathrm{kBq}(8.0-13.5 \mu \mathrm{Ci})$ of ${ }^{14} \mathrm{C}$ radioactivity $/ \mathrm{kg}$ body weight over $10 \mathrm{~cm}^{2}$ area of skin would be adequate to detect penetration of $1 \%$ of the applied dose.

\section{In Vitro}

56. For finite dose experiments, the applied dose should mimic the 'in-use' conditions. It should be given as an appropriate quantity of test preparation (usually as a volume) spread on the skin surface. Up to $10 \mathrm{mg} / \mathrm{cm}^{2}$ or $10 \mu \mathrm{L} / \mathrm{cm}^{2}$ could be used. Larger amounts tend to run-off in actual exposure conditions (9)(12)(15)(16). Smaller volumes may be appropriate, based on the physicochemical properties of the test preparation, for example low viscosity liquids.

57. An infinite dose is the amount of test preparation applied to the skin where the maximum absorption rate is achieved and maintained. Thus, the concentration of test substance in the donor compartment is not significantly diminished during the study.

58. Infinite dose experiments, with typical doses of $100 \mu \mathrm{L} / \mathrm{cm}^{2}$ (or $>10 \mathrm{mg} / \mathrm{cm}^{2}$ ) and more, may be appropriate to obtain steady-state conditions from which the steady-state flux or absorption rate and the Kp value (cm/hour) can be calculated. Such a volume ensures continuous excess of test preparation in the donor compartment (16).

59. In some cases a spreader may be required to evenly distribute creams, pastes and other viscous test preparations over the application site. In those cases the spreader should be checked for retention of material and the actual applied dose should be determined by subtraction of the amount of retained material from the applied dose.

60. For studies with radio-labelled test substance an application of $37 \mathrm{kBq}(1 \mu \mathrm{Ci})$ of ${ }^{14} \mathrm{C}$ over 1 $\mathrm{cm}^{2}$ area of skin preparation is more than adequate to detect penetration of $1 \%$ of the applied dose.

\section{Occlusion Conditions}

\section{In Vivo and In Vitro}

61. To mimic normal exposure conditions, the surface of the skin may be unoccluded, semioccluded or occluded. Unoccluded conditions allow any volatile component of the test preparation to evaporate and the normal drying process to occur. In addition, unoccluded or semi-occluded conditions can avoid skin integrity damage caused by excessive hydration (44), which may occur with occlusion. The open atmosphere design of the in vitro approach also allows a more direct comparison with the in vivo approach where the application site is normally protected but not occluded (12)(31).

62. It is also possible to study the effects of occlusion and reduced evaporation by covering the donor chamber with a glass coverslip or parafilm. It is important that the duration of any occlusion should reflect the human exposure scenario. 


\section{Temperature}

\section{In Vitro}

63. Alterations in skin temperature may affect the absorption process since diffusion is temperature dependent (16). Thus, the receptor fluid in contact with the skin must be maintained at a constant temperature, normally $32 \pm 1^{\circ} \mathrm{C}$, which is considered to be the temperature of human skin.

64. Most in vitro systems use a water bath or a solid block heater to maintain the temperature of mounted skin preparations. A suitable thermometer should be used to demonstrate that the system (when stable) maintains the skin (or receptor fluid) at the target temperature.

65. It is not necessary to measure the surface temperature and \% relative humidity of every skin preparation for each test, but it should be demonstrated that the system performs to the required standard.

\section{Duration of Exposure and Sampling}

66. For in vivo and finite-dose in vitro studies, the exposure time (time from application to washoff, or to study termination if no wash-off is performed) should reflect 'in-use' conditions and thereby allow a quantification of the amount of chemical which has been absorbed over a time course(s) which relates to potential human exposure (12). For example, for a rinse-off product this may be as short as a few minutes or, for a leave-on product, could be 24 hours or longer. In the case of industrial chemicals and agrochemicals the exposure period should reflect the occupational exposure. For example, an agrochemical product or its spray strength dilution may be exposed for a 6-hour period (15). Exposure times for industrial materials should mimic any specific work-place exposure within the limitations of the methods.

67. Washing of the skin surface terminates the exposure period. The procedure to remove the test preparation from the surface of the skin should mimic normal practice 'in-use'. The most appropriate method of washing the skin is use of an aqueous soap, or that which reflects hygiene practice. The use of natural sponge or cotton swabs is recommended to more closely represent the mechanical surface contact associated with using soap. Skin washing may be undertaken at a defined time point within a study in addition to the terminal procedure described above. For in vitro studies, the small size and delicate nature of the skin preparation can make the washing of the skin surface less efficient than that achieved in vivo. This would lead to an underestimate of the dislodgeable dose. All materials used in these washing procedures must be appropriately rinsed, dissolved or extracted for a recovery determination. Since the efficiency of the washing procedure may vary with the nature of test substance / preparation it is recommended to establish the efficiency of the washing procedure. This could be done by applying the test substance on the surface of skin samples isolated in diffusion cells and removing it immediately after this application. The wash solution should then contain $100 \%$ of the test substance and the skin sample $0 \%$ of the test substance

\section{In Vivo}

68. The absorption profile is dependent on the thermodynamic properties of the test substance in the test preparation therefore the sampling period should be adapted accordingly. Termination times should allow an estimate of absorption over the period of interest, to provide data on systemic exposure per hour or per day. A 24-hour termination time point will allow an estimation of the daily systemic exposure. Other groups maintained for longer periods post-exposure are commonly necessary 
to understand the fate of the skin residue post-exposure. A preliminary investigation may be useful in identifying the optimum period for any individual chemical.

\section{In Vitro}

69. To allow for any potential inertia between entry of the chemical into the stratum corneum and its partitioning into the receptor phase, it is important to sample the receptor fluid for at least a 24hour period. It may be necessary to extend the sampling period beyond 24 hours in cases where the lag phase is particularly long. However, an increase of exposure time over 24 hours may alter the skin integrity depending on the receptor fluid used

70. When an infinite application is used, an exposure period beyond 24 hours may be appropriate in order to achieve a steady-state flux and enable the calculation of a permeability coefficient.

71. The objective is to determine the absorption profile and to do this, 6-12 sampling points over a 24 hour period are normally required. However, the actual frequency of receptor fluid sampling should be based on the information available prior to the experiment such as the physicochemistry of the test substance/type of formulation and likely lag time. Analytical considerations may require relatively high sample volumes to be taken with a consequent reduction in sampling frequency. In static cells, correction for the change in volume of the receptor fluid (and hence concentration of penetrant) should be made after sampling by replacement with fresh receptor fluid.

\section{Terminal Procedures}

\section{In Vivo and In Vitro}

\section{Skin Fractionation}

72. Skin fractionation may be performed to further define the localisation of the test substance within the skin, as required by the objectives of the study (15). This can be particularly useful in in vivo studies where sequential groups are analysed at different times post-exposure. Tape stripping can be used to remove stratum corneum from skin (e.g., 15-25 strips for human skin) (16)(58). This procedure is normally achievable in vivo, but in vitro can be difficult with epidermal membranes, rodent skin, study durations of over 24 hours or where the test preparation alters the stratum corneum. Cyanoacrylic glue on a solid glass slide can be used to remove the stratum corneum with skin appendages. Freezing or otherwise fixing skin preparations allows the use of a microtome to cut the samples in horizontal slices (16). Histological evaluation is normally required to verify the level from which the layers originated. The above procedures can be used to fractionate the skin, the layers can then be dissolved in scintillation fluid or analysed for test material / metabolites using suitable methods to quantitate the distribution of test material in skin. An alternative method of evaluating distribution within skin is to take vertical sections through the skin and use autoradiography or other analytical techniques to visualise the test substance (15). Other procedures such as visualisation by confocal microscopy may be used when the detection methods can be shown to be adequately accurate (specific and sensitive). These methods would normally be regarded as semi-quantitative, but can be adequate to give a good indication of test substance distribution, and hence its immediate bioavailability (15). 


\section{Analysis}

\section{In Vivo}

73. The quantity of test substance and/or metabolites in the following compartments should be determined:

- $\quad$ application system (e.g. spreader, O-ring, cover, bandage, activated charcoal, etc.)

- dislodgeable dose from skin surface (washings, sponges, etc.)

- $\quad$ skin from the treated site (which may be fractionated into stratum corneum, epidermis and dermis)

- desquamated skin (from protective dressings post-exposure)

- urine, faeces, and cage washing

- expired gas should be collected daily if it is likely that volatile radioactive metabolites ( $>5 \%$ of applied dose) would be expired (based on information from metabolism studies)

- blood, sample of untreated skin target tissue (optional), and remaining carcass

- $\quad$ solvent washings of any other potentially contaminated material (e.g. surgical equipment used for skin sampling and metabolism bowls)

An additional study can be conducted to determine whether test compound in the layers of skin at the end of a study will ultimately diffuse through the skin, remain in the skin or be removed by the surface shedding of the stratum corneum. Results of this study may show that skin levels of test compound need not be considered to be percutaneously absorbed.

\section{In Vitro}

74. For finite dose applications the quantity of test substance and/or metabolites in the following compartments should be determined:

- $\quad$ applicator (spreader, glass rod, loop, etc.)

- donor chamber

- dislodgeable dose from skin surface (washings, sponges, etc.).

- $\quad$ stratum corneum, when sampled (tape strips, etc.)

- $\quad$ skin preparation

- $\quad$ receptor fluid and receptor chamber

75. Microcirculation is obliterated in in vitro skin. Consequently, dermal tissue can retain penetrating compounds, which would have left the skin to join the systemic compartment in vivo. Thus such a retention into the dermis in vitro must be taken into account when calculating absorbed 
dose. The epidermis renews itself by continuous outward proliferation, differentiation and desquamation. Xenobiotics found after topical application in the skin, particularly the stratum corneum and the pilosebaceous unit, may be lost from the skin in vivo via desquamation or sebum secretion. Because these processes are not functional in vitro, the terminal stratum corneum levels may be elevated compared with in vivo levels.

76. It has been demonstrated that lipophilic test substances may be artificially retained in skin even when polyethylene glycol 20 oleyl ether or alcohol-water solutions have been used as receptor fluids to solubilize the compounds (59). The amount of artificial retention of lipophilic test compounds by skin will vary with the compound and cannot be predicted at this time. It is therefore necessary that skin levels of test compound measured at the end of a study be included with the receptor fluid levels to determine total percutaneous absorption. Skin absorption may be expressed using receptor fluid alone provided that this can be justified.

\section{In Vivo and In Vitro}

77. An adequate mean recovery is in the range of $100 \pm 10 \%$. Under certain circumstances, for example the test of a volatile substance that had to be trapped in a filter, recovery boundaries $100 \pm$ $20 \%$ may be acceptable. The reason for not meeting the goal of $100 \pm 10 \%$ recovery should be explained in the report. There may be reasons why a full recovery analysis cannot be done with unlabelled test substance, for example:

- analytical problems (e.g. limit of determination, extraction and quantification from the complex matrices, similarity of the analyte with physiological substances such as fatty acids, urea)

- test substance degradation is significant

78. However, unlabeled test compounds should only be used in in vitro studies with lipophilic compounds if analytical sensitivity permits skin levels of test compound to be measured at the end of the study (See comments in In Vitro Section of Analysis.)

79. For infinite dose applications, steady-state flux or permeability coefficient (Kp) are determined. Recovery determination is not relevant because the only important end-point is the appearance of test substance in the receptor fluid (14). 


\section{REFERENCES}

(1) OECD (2004). Test Guideline 427:Skin Absorption: In Vivo Method. OECD, Paris

(2) OECD (2004). Test Guideline 428:Skin Absorption: In Vitro Method. OECD, Paris

(3) Zendzian RP (1994). Pesticide assessment guidelines. Subdivision F: Hazard evaluation: Humans and domestic animals. Series 85-3. US Environmental Protection Agency.

(4) EC (1994). Commission Directive 94/79/EC amending Council Directive 91/414/EEC concerning the placing of plant protection products on the market. Official Journal of the European Communities, No. L 354, 21 December 1994.

(5) US EPA (1993). Subchapter E - Pesticide Programs. Data requirements for registration. 40 CFR 158 (revised).

(6) US EPA (1992) Dermal Exposure Assessment: Principles and Applications. Exposure Assessment Group, Office of Health and Environmental Assessment.

(7) Bronaugh RL, Wester RC, Bucks D, Maibach HI and Sarason R (1990) In vivo percutaneous absorption of fragrance ingredients in rhesus monkeys and humans. Fd. Chem. Toxic. 28, 369373.

(8) Feldman RJ and Maibach HI (1970) Absorption of some organic compounds through the skin in man. J. Invest. Dermatol. 54, 399-404.

(9) Kemppainen BW, and Reifenrath WG. (1990). Methods for skin absorption. CRC Press, Boca Raton.

(10) Bronaugh RL and Collier, SW. (1991). Protocol for In vitro Percutaneous Absorption Studies, in In vitro Percutaneous Absorption: Principles, Fundamentals and Applications, R L Bronaugh and H I Maibach, Eds., CRC Press, Boca Raton, 1991, pp.237-241.

(11) Bronaugh RL and Maibach HI. (1991). In vitro percutaneous absorption: principles, fundamentals, and applications. CRC Press, Boca Raton.

(12) European Centre for Ecotoxicology and Toxicology of Chemicals (1993). Monograph No. 20, Percutaneous Absorption, ECETOC, Brussels.

(13) Diembeck W, Beck H, Benech-Kieffer F, Courtellemont P, Dupuis J, Lovell W, Paye M, Spengler J, Steiling W, (1999). Test Guidelines for In Vitro Assessment of Dermal Absorption and Percutaneous Penetration of Cosmetic Ingredients, Fd Chem Tox, 37, 191-205.

(14) Recommended Protocol for In vitro Percutaneous Absorption Rate Studies (1996). Federal Register, Vol 61, No. 65.

(15) Howes D, Guy R, Hadgraft J, Heylings JR et al. (1996). Methods for assessing percutaneous absorption. ECVAM Workshop Report ATLA 24 81-106. 
(16) Schaefer H and Redelmeier TE. (1996). Skin barrier: principles of percutaneous absorption. Karger, Basel.

(17) Roberts MS and Walters KA. (1998). Dermal absorption and toxicity assessment. Marcel Dekker, New York.

(18) Franz TJ. (1975). Percutaneous absorption: on the relevance of in vitro data. J Invest. Dermatol. 64: 190-195.

(19) Bronaugh RL, Stewart RF, Congdon EF, and Giles Al, Jr. (1982). Methods for in vitro percutaneous absorption studies. I. Comparison with in vivo results. Toxicol Appl Pharmacol. 62: 474 .

(20) Scott RC and Ramsey JD. (1987). Comparison of the in vivo and in vitro percutaneous absorption of a lipophilic molecule (Cypermethrin, a pyrethroid insecticide). J Invest. Dermatol. 89: 142-146.

(21) Grissom RE Jr, Brownie C, and Guthrie FE. (1987). In vivo and in vitro dermal penetration of lipophilic and hydrophilic pesticides in mice. Bull. Environ. Contam. Toxicol. 38: 917-924.

(22) Bronaugh RL, and Maibach HI. (1985). Percutaneous Absorption of nitroaromatic compounds. In vivo and in vitro studies in the human and monkey. J Invest. Dermatol. 84: 180-183.

(23) Moody RP, Franklin CA, Ritter L and Maibach HI. (1990) Dermal absorption of the phenoxy herbicides 2,4-D, 2,4-D amine, 2,4-D isooctyl, and 2,4,5-T in rabbits, rats, rhesus monkeys, and humans: a cross species comparison. J Toxicol Environ Health 29(3) 237-45.

(24) Bronaugh RL, and Franz TJ (1986). Vehicle effects on percutaneous absorption: in vivo and in vitro comparisons with human skin. Br. J Dermatol. 115: 1-11.

(25) Scott RC, Corrigan MA, Smith F and Mason H. (1991) The influence of skin structure on permeability: An intersite and interspecies comparison with hydrophilic penetrants. J Invest Dermatol 96: 921-925.

(26) Yang JJ, Roy TA and Mackerer CR (1986). Percutaneous absorption of anthracene in the Rat: comparison of in vivo and in vitro results. Toxicol. Indus. Health 2: 79-84.

(27) Yang, JJ, Roy TA, and Mackerer CR (1986). Percutaneous absorption of benzo(a)pyrene in the rat: Comparison of in vivo and in vitro results. Toxicol. Indus. Health, 2: 409-416.

(28) Scott RL, Walker M and Dugard PH (1986). In vitro percutaneous absorption experiments: a technique for the production of intact membranes from rat skin. J. Soc. Cosmet. Chem. 37 3541.

(29) Hotchkiss SA, Chidgey JAJ, Rose S and Caldwell J (1990). Percutaneous absorption of benzyl acetate through rat skin in vitro. 1. Validation of an in vitro model against in vivo data. Fd Chem Toxic. 24: 443-447.

(30) Ng KME, Chu I, Bronaugh RL, Franklin CA and Somers DA (1991). Percutaneous absorption/ metabolism of phenanthrene in the hairless guinea pig: Comparison of in vitro and in vivo results. Fundam.Appl.Toxicol. 16, 517-524. 
(31) Scott RC, Batten PL, Clowes HM, Jones BK and Ramsey JD (1992). Further validation of an in vitro method to reduce the need for in vivo studies for measuring the absorption of chemicals through rat skin. Fundam. Appl. Toxicol. 19: 484-492.

(32) Ng KME, Chu I, Bronaugh RL, Franklin CA and Somers DA (1992). Percutaneous absorption and metabolism of pyrene, benzo[a]pyrene, and $\mathrm{Di}(2$-ethylhexyl)phthalate: Comparison of in vitro and in vivo results in the hairless guinea pig. Toxicol. Appl. Pharmacol. 115; 216-223.

(33) Hotchkiss SAM, Hewitt P, Caldwell J, Chen WL and Rowe RR (1992). Percutaneous absorption of nicotinic acid, phenol, benzoic acid and triclopyr butoxyethyl ester through rat and human skin in vitro: Further validation of an in vitro model by comparison with in vivo data. Fd. Chem. Toxic. 30: 891-899.

(34) Hadgraft JD, Beutner D, and Wolff HM (1993). In vivo-in vitro comparisons in the transdermal delivery of nitroglycerin. Int. J Pharm. 89(1): p. R1-R4.

(35) Beck H, Bracher M and Bartnik FG (1994). Percutaneous absorption of hair dyes: an interlaboratory comparison of in vivo and in vitro data with rat and pig. In vitro Toxicol. 7: 305312.

(36) van de Sandt JJ, Meuling WJ, Elliott GR, Cnubben NH, Hakkert BC(2000). Comparative in vitro-in vivo percutaneous absorption of the pesticide propoxur. Toxicol-Sci. 58(1): 15-22.

(37) Cnubben, NH, Elliott GR, Hakkert BC, Meuling WJ, van de Sandt JJ (2001). Comparative in vitro-in vivo Percutaneous Penetration of the Fungicide ortho-Phenylphenol. Regulatory Toxicology and Pharmacology Academic Press. Doi:10.1006/rtph.2001.1530: 1-11.

(38) Ramsey JD, Woollen BH, Auton TR and Scott RC (1994). The Predictive Accuracy of In vitro Measurements for the Dermal Absorption of a Lipophilic Penetrant (Fluazifop-Butyl) through Rat and Human Skin. Fundam. Appl. Toxicol. 23, 230-236.

(39) Roper CS Howes D, Blain PG and Williams FM (1995) Prediction of the percutaneous penetration and metabolism of dodecyl decaethoxylate in rats using in vitro models. Arch. Toxicol. 69: 649-654.

(40) Dick IP, Blain PG, and Williams FM (1997). The percutaneous absorption and skin distribution of lindane in man. In vivo studies. Hum. Exp. Tox. 16: 645-51.

(41) Dick IP, Blain PG, and Williams FM (1997). The percutaneous absorption and skin distribution of lindane in man. II. In vitro studies. Human and Experimental 16: 652-657.

(42) Squier CA, Kremer, M, and Wertz PW (1997). Continuous flow mucosal cells for measuring the in vitro permeability of small tissue samples. J Pharma Sci 86: 82-84.

(43) Scott RC and Clowes HM. (1992). In vitro percutaneous absorption experiments: A guide to the technique for use in toxicology assessments. Tox Methods 2113.

(44) Bronaugh RL and Stewart RF (1985). Methods for in vitro percutaneous absorption studies IV: the flow-through diffusion cell. J Pharm Sci 7464. 
(45) Clowes HM, Scott RC and Heylings JR (1994). Skin Absorption: Flow-Through or Static Diffusion Cells. Toxic In vitro 8827.

(46) Scott RC, Carmichael NG, Huckles KR, Needham D, and Savage T (1993). Methods for measuring dermal penetration of pesticides. Fd Chem Toxic 31523.

(47) Bronaugh, RL and Stewart, RF (1986). Methods for in vitro percutaneous absorption studies VI: Preparation of the barrier layer. J Pharm Sci 75487.

(48) Collier SW, Sheikh NM, Sakr, A., Lichtin JL, Stewart RF and Bronaugh RL (1989). Maintenance of skin viability during in vitro percutaneous absorption/metabolism studies. Tox Appl Pharmacol 99522.

(49) Burch GE, and Winsor T (1942). Diffusion of water through dead plantar, palmar and torsal human skin and through toe nails. Arch Dermatol Syph 5339.

(50) Dugard PH, Walker M, Mawdsley SM and Scott RC. (1984). Absorption of some glycol ethers through human skin in vitro. Environ Health Perspect 57193.

(51) Southwell D and Barry BW (1983). Penetration enhancers for human skin: mode of action of 2pyrolidone and dimethylformamide on partition and diffusion of model compounds water, nalcohols and caffeine. J Invest Dermatol 80507.

(52) Harrison SM, Barry BW and Dugard PH (1984). Effects of freezing on human skin permeability. J Pharm Pharmacol 36 261-262.

(53) Swarbrick J, Lee G and Brom J (1982). Drug permeation through human skin. I. Effects of storage conditions of skin. J Invest Dermatol 7863.

(54) Hawkins GS and Reifenrath WG (1984). Development of an in vitro model for determining the fate of chemicals applied to the skin. Fundam Appl Toxicol 45133.

(55) Bronaugh RL, Stewart RF, and Simon M (1986). Methods for in vitro percutaneous absorption studies VII: Use of excised human skin, J Pharm Sci 751094.

(56) Benech-Kieffer F, Wegrich P and Schaefer H (1997). Transepidermal water loss as an integrity test for skin barrier function in vitro: assay standardization. In: Brain KR, James VJ and Walters KA, editors, Perspectives in Percutaneous Penetration Vol 5a, STS Publishing, Cardiff, p. 56.

(57) Brain KR, James VJ and Walters KA (1995). Validation of the integrity of epidermal membranes during assessment of percutaneous penetration. In: Brain KR, James VJ and Walters KA, editors, Prediction of Percutaneous Penetration Vol 4a, STS Publishing, Cardiff, C109.

(58) Trebilcock KL, Heylings JR and Wilks MF (1994). In vitro tape stripping as a model for in vivo skin stripping. Toxicol In vitro 8665.

(59) Bronaugh RL and Stewart, RF (1984). Methods for in vitro percutaneous absorption studies III. Hydrophobic compounds, J Pharm Sci 731255. 


\section{$\underline{\text { Additional Reference Material }}$}

The following publications from the PPP conference series are a very useful source of information in the field of percutaneous absorption and the methods used to predict the penetration of chemicals through the skin barrier.

Prediction of Percutaneous Penetration : Methods, Measurements, Modelling (1990).

Edited by RC Scott, RH Guy and J Hadgraft. IBC Technical Services Ltd, London.

Prediction of Percutaneous Penetration : Methods, Measurements, Modelling: Volume 2 (1991). Edited by RC Scott, RH Guy, J Hadgraft and H Bodde. IBC Technical Services Ltd, London.

Prediction of Percutaneous Penetration : Volume 3b (1993). Edited by KR Brain, VJ James, J Hadgraft and KA Walters. STS Publishing, Cardiff.

Prediction of Percutaneous Penetration : Volume 4b (1996). Edited by KR Brain, VJ James and KA Walters. STS Publishing, Cardiff.

Perspectives in Percutaneous Penetration : Volume 5b (1998). Edited by KR Brain, VJ James and KA Walters. STS Publishing, Cardiff.

Perspectives in Percutaneous Penetration : Volume 6b (2000). Edited by KR Brain and KA Walters. STS Publishing, Cardiff.

Perspectives in Percutaneous Penetration : Volume 7b (2002). Edited by KR Brain and KA Walters. STS Publishing, Cardiff. 


\section{GLOSSARY OF TERMS}

Absorbed dose (in vivo): comprises that present in urine, cage wash, faeces, expired air (if measured), blood, tissues (if collected) and the remaining carcass, following removal of application site skin.

Absorbed dose (in vitro): mass of test substance reaching the receptor fluid or systemic circulation within a specified period of time.

Absorbable dose (in vitro and in vivo) represents that present on or in the skin following washing.

Absorption (Dermal, Percutaneous and Skin absorption): diffusion of chemicals from the outer surface of the skin to the receptor fluid or systemic circulation.

Absorption profile: a graphical representation of cumulative absorption as a function of time.

Absorption rate: mass of test substance passing through a unit area of skin into the receptor fluid or systemic circulation, per unit time (in $\mu \mathrm{g} / \mathrm{cm}^{2} / \mathrm{h}$ ).

Adsorption: reversible binding or adherence the test substance to any component of the test system.

Applied dose: mass of test preparation containing a specified mass of test substance applied per $\mathrm{cm}^{2}$ of skin.

Dermal delivery: sum of the applied dose found in the treated skin and the absorbed dose at the end of the experiment.

Dislodgeable dose: mass of test substance that is removable from the application site.

Exposure period: time from application of test preparation to removal at skin washing.

Finite dose: amount of test preparation applied to the skin where a maximum absorption rate of the test substance may be achieved for a certain time interval but is not maintained.

Flux: mass of test substance passing through a unit area of skin per unit of time under steady-state conditions (in $\mu \mathrm{g} / \mathrm{cm}^{2} / \mathrm{h}$ ).

'in-use' preparation: the preparation of test substance which relates directly to potential human exposure (e.g. cosmetic or agrochemical formulations and dilutions thereof, a mixture of industrial chemicals in a solvent, etc.).

Infinite dose: amount of test preparation applied to the skin where a maximum absorption rate of the test substance is achieved and maintained.

Lag time: derived from a graph of cumulative absorbed dose and time. Intercept of the tangent of the linear part of the absorption profile with the $\mathrm{x}$-axis.

Penetration enhancer: adjuvant, which facilitates penetration of the test substance through skin. 
Percentage absorption: the mass of test substance absorbed (over a given time period) divided by the mass of test substance applied multiplied by 100 .

Permeability coefficient $(\mathbf{K p})$ : a value, in units of $\mathrm{cm} / \mathrm{h}$, that represents the rate at which a chemical penetrates the skin. This is calculated from the flux divided by the applied concentration.

Steady-state: the part of an absorption profile where the absorption rate remains constant.

Test substance: a single chemical entity whose penetration characteristics are under investigation.

Test preparation: actual material that is applied to the skin. Usually the test preparation will be the 'in-use' preparation that reflects actual use conditions; alternatively it may be a mixture of the test substance in a carrier or solvent to facilitate application to the skin.

Unabsorbed dose: represents that washed from the skin surface after exposure and any present on the non-occlusive cover, including any dose shown to volatilise from the skin during exposure. 